\title{
HYSTERESIS OF CONTACT ANGLE OF WATER ON PARAFFIN. EFFECT OF SURFACE ROUGHNESS AND OF PURITY OF PARAFFIN ${ }^{1}$
}

\author{
B. Roger Ray ${ }^{2}$ and F. E. Bartell \\ Department of Chemistry, University of Michigan, Ann Arbor, Michigan \\ Received October 24, 1952
}

INTRODUCTION

Many investigators have measured the contact angles of water on paraffin with considerable variation in results. It is nevertheless a common belief that the system has a unique characteristic value which is easily reproducible and free of complications. The system has been much used as a standard for calibration and for experiment as well as for theoretical calculations pertaining to surface forces. Fowkes and Harkins (1) reported no hysteresis for the contact angle of water on a sample of paraffin solidified in air and examined by the tilting-plate method, but before reading the instrument they permitted evaporation to take place for several minutes or else shook the cell "to produce equilibrium." Similar experiments carried out in this laboratory under conditions where evaporation and mechanical jarring were carefully prevented have invariably shown the occurrence of hysteresis. Thiessen and Schoon (2) reported the absence of hysteresis on single crystals of paraffin but based their conclusions on rather variable results. The objective of the present research was to extend earlier studies of hysteresis in the paraffin-water system by investigating the effect of purification of the paraffin and of the gross physical character of the paraffin surface, and to attempt to show conclusively either the permanent nature of hysteresis or the conditions under which hysteresis might be induced or might be eliminated.

\section{Experimental Procedure}

\section{Methods Used for Contact-Angle Measurements}

Contact angles were measured by four methods, the choice of method depending upon the conditions of the experiment. All measurements were carried out in an air thermostat regulated to $25.0 \pm 0.1^{\circ}$. The contact-

1 The data in this paper were taken from a portion of the thesis of B. Roger Ray, submitted to the School of Graduate Studies of the University of Michigan in partial fulfilment of the requirements for the Ph.D. degree, December, 1945.

${ }^{2}$ Present address: Department of Chemistry, University of Illinois, Urbana, Illinois. 
angle device and cell were supported independently of the thermostat so as to eliminate vibration.

For the vertical-rod (VR) method (3) and the tilting-plate (TP) method (4), a contact-angle device was constructed which consisted, in the main, of a sample holder attached to a circular disk graduated in degrees. The elements were so mounted that with the fine rack-and-pinion device the glass rod or plate could be moved easily and accurately in both horizontal and vertical directions, and could be rotated about a point so fixed that the center of rotation remained exactly at the solid-water-air interface.

The controlled-drop-volume (CDV) method, a modification of the usual drop-on-plate method (5), made use of a pipet with a very fine tip (approx. $0.02 \mathrm{~mm}$. outside diameter) from which water was either forced out to increase the volume of the small drop when forming an advancing angle or sucked back in when forming a receding angle. Sensitive and positive control of the drop volume was achieved, and the fine tip did not appreciably distort the drop. A greatly magnified silhouette of the drop was projected onto a ground-glass screen and the tangent erected upon the image.

The drop-on-capillary-tip (CT) method employed an apparatus developed by Bartell and Smith (6) for their studies on the wetting of metal surfaces. The capillary tip was sealed into an all-glass contact-angle cell; the absence of all stopcocks, grease, rubber, corks, and sealing compositions insured freedom from contamination. A fresh paraffin surface could be formed in a vacuum on the flat tip in the cell either by melting a lump of paraffin previously placed on the tip (using a resistance coil suspended above the tip) or by volatilization onto the tip from a drop of paraffin held within the resistance coil by capillarity. Water could then be introduced to saturate the vapor space (in some cases air or nitrogen was also introduced). Finally, water could be forced onto the tip to form a drop.

\section{Measurement of Contact Angles}

All parts of the apparatus coming into contact with paraffin or water were freshly cleaned in hot chromic acid, followed by soaking in water or by flaming. Thermal equilibrium and aqueous saturation of the vapor space surrounding the paraffin surface were achieved in each case before the formation of the interface.

For all the water-paraffin systems examined, both stable advancing and stable receding angles were found. The angles quickly reached stable values and no appreciable changes with time were observed. Ordinarily, angles were measured at 2,5 , and $15 \mathrm{~min}$. Receding angles were formed after the paraffin had been covered with water for at least 2 min. The reproducibility of measurements varied, depending first upon the physical 
character of the paraffin surface, and secondly upon the method used. The tilting-plate method proved inferior to the other methods in accuracy and convenience.

\section{Materials}

Double-distilled water was stored in Pyrex, and portions were withdrawn from the interior by siphon. The surface tension was frequently

\section{TABLE I}

Contact Angles in Air of Water on Surfaces of Paraffin

(Surfaces formed in air)

\begin{tabular}{|c|c|c|c|c|c|c|c|}
\hline \multirow{2}{*}{ Experiment } & \multirow{2}{*}{$\begin{array}{l}\text { Method of } \\
\text { formation } \\
\text { of surface }\end{array}$} & \multirow{2}{*}{ Appearance of surface } & \multirow{2}{*}{$\begin{array}{l}\text { Method } \\
\text { used }\end{array}$} & \multicolumn{3}{|c|}{ Contact angle values } & \multirow{2}{*}{$\begin{array}{c}\text { Hyster- } \\
\text { esis } \Delta \theta\end{array}$} \\
\hline & & & & $\theta^{a}$ & $\theta^{r}$ & Av. & \\
\hline Sample $I^{b}$ & & & & deg. & deg. & deg. & $d e g$. \\
\hline $\mathrm{I}-A$ & $A$ & Heavy, opaque, rough & TP & $120 \pm 3$ & & & \\
\hline $\mathrm{I}-B$ & $B$ & $\begin{array}{l}\text { Thin, opaque, waxy- } \\
\text { like }\end{array}$ & VR & $112 \pm 1$ & $104 \pm 2$ & 108 & 8 \\
\hline $\begin{array}{l}\text { Sample II } \\
\text { II- } A\end{array}$ & $B$ & Same as in $I-B$ & VR & $111 \pm 2$ & $102 \pm 3$ & 106 & 9 \\
\hline $\begin{array}{l}\text { Sample III } \\
\text { III- } A\end{array}$ & $B$ & $\begin{array}{l}\text { More crystalline than } \\
\text { I- } B\end{array}$ & VR & $115^{j}$ & $106^{f}$ & 110 & 9 \\
\hline $\begin{array}{c}\text { III- } B \\
\text { Sample IVe }\end{array}$ & $B$ & Same as III- $A$ & $\mathrm{CT}$ & $112 \pm 1$ & $105 \pm 1$ & 108 & 7 \\
\hline IV $-A$ & $C$ & $\begin{array}{l}\text { Heavy, coarse, crystal- } \\
\text { line, transparent }\end{array}$ & VR & $132 \pm 4$ & $97 \pm 2$ & 114 & 35 \\
\hline IV $-B$ & $D$ & $\begin{array}{l}\text { Thin, crystalline, nearly } \\
\text { transparent }\end{array}$ & VR & $115 \pm 1$ & $110 \pm 2$ & 113 & 5 \\
\hline
\end{tabular}

a Method of formation of surface: $A$, microscope slide quickly dipped into and out of sample held at $110^{\circ}$. Paraffin solidified on contact; $B$, glass rod immersed a few seconds in sample held at $100^{\circ}$ and slowly withdrawn. Paraffin solidified in few seconds; $C$, glass rod quickly dipped as in I- $A$. Paraffin solidified on contact; $D$, glass rod heated in sample at $100^{\circ}$ and then withdrawn. Paraffin solidified in $1 \mathrm{~min}$.

${ }^{b}$ Commercial paraffin, specially filtered, m.p. $56-58^{\circ}$.

c Commercial paraffin: Parowax.

${ }^{d}$ First purification product from Parowax, b.p. $191-198^{\circ}$ at $2 \mathrm{~mm}$.

- Final purification product from Parowax, b.p. $185-188^{\circ}$ at $1 \mathrm{~mm}$.

$f$ Single determination.

checked with a ring tensiometer. Two commercial samples of paraffin from two different companies were examined and are designated as sample I and sample II.

Most of the measurements were made on a purified sample, a narrowboiling fraction of paraffin freed of nonhydrocarbon substance and of contaminants by the following procedure. Fifteen hundred grams of 
Parowax (sample II) was stirred for several hours with warm concentrated sulfuric acid. This was repeated twice. The paraffin, tan in color, was washed free of acid with several portions of warm water. This product and $500 \mathrm{~g}$. of clean sodium metal were placed in a three-necked flask. After flushing with nitrogen, the temperature was raised to $110^{\circ} \mathrm{C}$. and the contents were stirred. After $4 \mathrm{hr}$., the paraffin, now brown in color, was forced into the flask of the distillation apparatus by a stream of nitrogen gas. This apparatus had previously been flushed with nitrogen

TABLE II

Contact Angles of Water on Surfaces of Purified Paraffin

(Surfaces formed in vacuum and in nitrogen)

\begin{tabular}{|c|c|c|c|c|c|c|c|c|}
\hline \multirow{2}{*}{$\begin{array}{l}\text { Experi- } \\
\text { ment }\end{array}$} & \multirow{2}{*}{$\begin{array}{l}\text { Method of } \\
\text { formation } \\
\text { of surface }\end{array}$} & \multirow{2}{*}{ Appearance of surface } & \multirow{2}{*}{$\begin{array}{c}\text { Composition } \\
\text { gas phase }\end{array}$} & \multirow{2}{*}{$\begin{array}{l}\text { Method } \\
\text { used }\end{array}$} & \multicolumn{3}{|c|}{ Contact angle values } & \multirow{2}{*}{$\begin{array}{l}\text { Hyster- } \\
\text { esis } \Delta \theta\end{array}$} \\
\hline & & & & & $\theta^{a}$ & $\theta^{r}$ & Av. & \\
\hline Sample IV & & & & & deg. & deg. & deg. & deg. \\
\hline$I V-C$ & $A$ & $\begin{array}{l}\text { Fairly transparent, } \\
\text { crystal formation, } \\
\text { eracks }\end{array}$ & $\begin{array}{l}\text { Water } \\
\text { vapor }\end{array}$ & CT & $114 \pm 2$ & $110 \pm 1$ & 112 & 4 \\
\hline IV $-D$ & $B$ & Same as in IV-C. & $\begin{array}{l}\text { Nitrogen } \\
\text { water }\end{array}$ & $\mathrm{CT}$ & $114^{b}$ & $110^{\mathrm{b}}$ & 112 & 4 \\
\hline IV $-E$ & C & $\begin{array}{l}\text { Opaque, similar to } \\
\text { deposit of white } \\
\text { smole }\end{array}$ & $\begin{array}{l}\text { vapor } \\
\text { Nitrogen }+ \\
\text { water } \\
\text { vapor }\end{array}$ & $\mathrm{CT}$ & $121^{b}$ & $108^{b}$ & 115 & 13 \\
\hline IV $-F$ & $D$ & $\begin{array}{l}\text { Film invisible except } \\
\text { interference pattern }\end{array}$ & $\begin{array}{l}\text { Nitrogen }+ \\
\text { water }\end{array}$ & CDV & $112 \pm 1$ & $112 \pm 1$ & 112 & $\begin{array}{l}\text { None } \\
\text { approx. }\end{array}$ \\
\hline \multirow[t]{3}{*}{ IV $-G$} & $E$ & $\begin{array}{l}\text { 1. Opaque, similar to } \\
\text { that in IV-E }\end{array}$ & $\begin{array}{l}\text { vapor } \\
\text { Air }+ \\
\text { water }\end{array}$ & $\mathrm{CDV}$ & $120-140$ & $96-110$ & & $\begin{array}{l}27 \\
\text { approx. }\end{array}$ \\
\hline & & $\begin{array}{l}\text { 2. Transparent, barely } \\
\text { detectable }\end{array}$ & Air + & $\mathrm{CDV}$ & $116^{b}$ & $108^{b}$ & 112 & 8 \\
\hline & & $\begin{array}{l}\text { 3. Film similar to that } \\
\text { in IV-F }\end{array}$ & $\begin{array}{l}\text { vapor } \\
\text { Air }+ \\
\text { water } \\
\text { vapor }\end{array}$ & $\mathrm{CDV}$ & $112 \pm 1$ & $112 \pm 1$ & 112 & $\begin{array}{l}\text { None } \\
\text { approx. }\end{array}$ \\
\hline
\end{tabular}

a Method of formation of surface: $A$, contact-angle cell sealed to distillation receiver. One drop of distillate, at $1 \mathrm{~mm}$. $\mathrm{N}_{2}$, caused to fall onto tip in cell. Cell evacuated to $10^{-4}$ $\mathrm{cm}$. and sealed off; $B$, small lump placed on tip in contact-angle cell. Cell flushed with $\mathrm{H}_{2}$ and evacuated. Paraffin was caused to vaporize by heat from resistance coil above tip; $C$, same as $B$ except $\mathrm{N}_{2}$ was used as inert gas; $D$, same as $C$ except only small amount of paraffin vaporized; $E$, similar to $C$ except condensation was on glass plates and coatings of different thicknesses were obtained.

${ }^{b}$ Single determination.

by evacuating and filling twice in succession. The nitrogen pressure was reduced to $2 \mathrm{~mm}$. and the paraffin slowly distilled, the fraction boiling at $191-198^{\circ} \mathrm{C}$. being labeled sample III. This fraction was re-treated with molten sodium metal (no color developed) and redistilled at less than 1 $\mathrm{mm}$. Sample IV, used for contact-angle measurements, was that portion collected at $185-188^{\circ} \mathrm{C}$.

The distillate was caused to flow from the condenser tube into a glass spout which swiveled at its upper end and contained a sealed-in iron strip 
by means of which, through manipulation of a magnet outside the glass walls, the paraffin melt could be directed into a receiving flask or directly into the contact-angle apparatus so positioned as to permit drops of distillate to fall onto the capillary tip in the cell.

\section{Results}

In Tables I and II are presented the values of the contact angles of water on various paraffin surfaces (advancing angles $=\theta^{a}$ and receding angles $=\theta^{r}$ ). Each experiment noted in the first column of each table summarizes the measurements made under one particular set of conditions which is outlined in the accompanying column. Also indicated is the physical appearance of the surface as it appeared to the eye. Table I deals with surfaces formed in the presence of air and upon which the contact angles were measured with the vapor space filled with air saturated with water vapor. Table II deals with purified paraffin (sample IV) the surfaces of which were formed in vacuum or at a low pressure of nitrogen, and on which the contact angles were measured with the vapor space filled as noted in col. 4 .

\section{Contact Angles on Surfaces Formed from Melts in Air}

The results of Expts. I- $A$ through II- $A$ are typical for ordinary paraffin surfaces. When the rate of solidification of the paraffin was rapid and the coating thick and rough, as in $\mathrm{I}-A$, the advancing angle was found to be as high as $120^{\circ}$. When the rate of solidification was slow and the thickness of the layer reduced, the surface became smoother and the angle dropped to $112^{\circ}$. Values intermediate between these limits were obtainable depending, it appeared, upon the roughness of the surface.

This roughness, to a major extent, is the result of crystallizing forces that lead to a surface composed of the planes, edges, and corners of crystals with many holes and fissures due to the high degree of imperfection. The commercial paraffins, being a mixture of constituents, were observed to solidify from melts as typical, white, opaque masses (presumably microcrystalline). Under comparable conditions the purified paraffin, represented by the narrow fraction designated as sample IV, solidified from melts as practically transparent surfaces with what appeared to be cleavage planes between relatively large crystals. Evidence of roughness effects in what may be called the limiting cases, is seen by comparing Expts. I-A and IV-A. The advancing contact angle for I- $A$ was $120^{\circ}$ while the very coarse crystalline character of the surface of sample IV gave an advancing angle of $132^{\circ}$. Angles between $132^{\circ}$ and $115^{\circ}$ could be obtained by varying the dipping procedure and, thereby, the physical character of the surface, 
The receding angles decreased with increasing surface roughness as can be seen by comparing Expts. IV $-A$ and IV- $B$. Although the measurements for them are not shown, intermediate type surfaces gave receding angles between $97^{\circ}$ and $110^{\circ}$.

Without exception, the surfaces described in Table I showed significant differences between the values of the advancing and receding angles. The magnitude of this hysteresis effect seemed, on the one hand, to be in proportion to the gross roughness of the surface, as illustrated by the $\Delta \theta$ value of $35^{\circ}$ in Expt. IV $-A$. On the other hand, for surfaces formed under similar conditions the magnitude of hysteresis decreased with increasing purity of the paraffin, as illustrated by Expts. I $-B$ and II $-A$, in which $\Delta \theta$ averages $9^{\circ}$, and Expt. IV $-B$ in which $\Delta \theta$ is $5^{\circ}$. Although the factors of surface roughness and surface purity could not be quantitatively distinguished, it was evident that the purified material was characterized by the largest as well as by the smallest hysteresis effects depending upon the physical nature of the surface.

It can be observed that the contact angles for the samples listed in Table I increased very slightly with purification. Comparing surfaces similar as to conditions of formation, we find the following approximate values:

Commercial paraffins, contact angles, $\theta^{a}=112^{\circ}$ and $\theta^{r}=103^{\circ}$.

First purification product, contact angles, $\theta^{a}=113^{\circ}$ and $\theta^{r}=106^{\circ}$

Final purification product, contact angles, $\theta^{a}=115^{\circ}$ and $\theta^{r}=110^{\circ}$

The increase, however, is only of significant magnitude for the receding angles. The trend may be due to traces of polar impurities that are removed in purification with a resulting increase in the free energy of the water-paraffin interface.

The average values of the angles for each sample as given in the next to last column of Table $I$ are found to fall within the range $106-114^{\circ}$ despite the quite varied hysteresis effects. This indicates that the main factor or factors responsible for hysteresis operate to increase the advancing angles and to decrease the receding angles by about the same amounts. In Expts. IV $-A$ and IV-B the hysteresis effects were $35^{\circ}$ and $5^{\circ}$, respectively, yet the average angles were $114^{\circ}$ and $113^{\circ}$.

The fairly good agreement between results obtained with the verticalrod and drop-on-capillary-tip methods is shown by Expts. III- $A$ and III- $B$. The tilting-plate method was found to give less reproducible results and to be more difficult to manipulate than the other methods.

\section{Contact Angles on Surfaces of Purified Paraffins}

The smallest hysteresis effect listed in Table I is $5^{\circ}$. This was for the purified material when the coating was as thin as could be produced by a 
simple dipping technique. According to certain theories of hysteresis, one might consider the persistence of the hysteresis effect to be due to the presence of air which led either to a certain polar heterogeneity of the surface by trace oxidation on the surface or to an adsorption of constituents from the surroundings. A second explanation might be that surfaces formed from melts, under the best of conditions, were of sufficient thickness and crystallinity, or surface roughness, to give rise to a measurable hysteresis effect. To furnish information on these points the experiments presented in Table II were carried out.

In Expt. IV-C the tip in the contact-angle cell was coated with sample IV by causing a drop of this distillate, under $1 \mathrm{~mm}$. pressure of purified nitrogen, to fall directly from the condenser tube onto the tip. This drop solidified to form a thin coat similar in appearance to that formed in Expt. IV-B. The cell was saturated with water vapor and the contact angle measured by the drop-on-capillary-tip method. In this experiment, at no time was the paraffin exposed to air. The measured contact angles of $114^{\circ}$ and $110^{\circ}$ agreed very well with the angles in air found in Expt. IV-B.

Further confirmation of the inertness of the paraffin was furnished by Expt. IV-D. A small lump of sample IV, broken from the mass that had been exposed to air for several days, was caused to flow over the tip in the evacuated contact-angle cell by the procedure outlined. After cooling, the cell was filled with pure nitrogen at 1 atm., saturated with water vapor, and the contact angles were measured. They were the same as before.

An evaporation technique was employed to investigate the wettability of films of paraffin thinner than those that could be produced from a melt. After placing a small lump of sample IV in the coil of resistance wire, the cell was sealed, evacuated, and a portion of the paraffin volatilized at a controlled rate by regulation of the current through the coil. That portion of the vapor striking the tip condensed thereon. A considerable amount of paraffin was volatilized in Expt. IV $-E$, the first carried out with this technique, and a fairly heavy coat was produced which, in contrast to a coat formed from a melt, was completely opaque and was amorphous and velvet-dull in appearance. A single determination of the contact angles showed a considerable hysteresis effect.

In the next experiment, IV $-F$, only a very small amount of paraffin was vaporized. The thinness of the film produced can be judged from the fact that the appearance of the tip was unaltered except for interference patterns seen when the surface was observed at an angle. An attempt to measure the contact angles on this surface by the drop-on-capillary-tip failed because the water extruded onto the tip instantly displaced the film. The experiment was repeated with success using the controlled- 
drop-volume method. This was accomplished as follows: After the film was deposited, the cell was filled with nitrogen and saturated with water vapor. The top of the cell was broken off while a positive flow of watersaturated nitrogen was supplied. The long glass tube with the very fine capillary point used for this method was lowered into position above the film and the drop was formed. The averages of the measured angles were $112^{\circ}$ advancing and $112^{\circ}$ receding. That is to say, a film of purified paraffin prepared in this manner exhibited no measurable degree of hysteresis. A residual hysteresis of less than $1^{\circ}$ would have remained undetected. Such a film was very fragile and, to avoid rupturing it, great care had to be taken in the placement and movement of the very small water drops.

The final experiments, outlined under IV-G, further confirmed the dependence of the hysteresis effect upon the character of the film. Angles as high as $140^{\circ}$ and as low as $96^{\circ}$ were recorded. When, however, the film was reduced in thickness to a few molecular diameters, the hysteresis effect disappeared. Since the measurements were carried out in the presence of air, it was established that the very thin films were, like thicker films, inert toward air, having the same contact angles in air as when surrounded by nitrogen. The practice was to measure the contact angles within a few minutes after the disposition of the film upon the glass plate. In one case a plate covered with a very thin film was allowed to age for $1 \mathrm{hr}$. in air at room temperature. The average of the advancing angles on this plate was $113 \pm 1^{\circ}$ and for the receding angles $110 \pm 2^{\circ}$. The optical appearance of this film had changed. It seems probable that surface crystallization was taking place.

\section{Significance of the "Average" Contact Angle}

Although the hysteresis effects on the purified paraffin varied in magnitude, the average angles for a number of the surfaces were nearly the same, $112^{\circ}$ approximately. The concept of physical roughness of surface can be postulated to explain the relationship observed. Adam (7), Wenzel (8), Coghill and Anderson (9), and Cassie and Baxter (10) have discussed surface roughness from various points of view.

Roughness, which stems from the fundamentally crystalline nature of solids, is presumed to be the result of a complex variety of peaks, planes, edges, holes, and fissures, which altogether comprise the surface. Various orders of roughness, from the macroscopic, to the microscopic, to the submicroscopic, or even to the molecular, exist. Within limits it may be permissible to consider that along any line on the macroscopic plane surface of a given solid the same average roughness exists and that a liquid caused to advance across the solid surface, or to recede, can be considered to flow up and down the slopes of a continuous series of peaks and depressions. Any effect of the angle these slopes make with the hori- 
zontal would be the effect of the resultant angle of all the actual irregularities.

If a liquid having a contact angle against a solid surface of, say, $60^{\circ}$ for the case in which the surface was ideally plane and smooth is caused to advance over the same material in roughened form, say with a roughness angle of $15^{\circ}$, then the experimentally observed apparent angle should be $75^{\circ}$. If, on the other hand, the liquid is caused to recede, the observed apparent angle should be $45^{\circ}$. These are the two limiting conditions characteristic of the system which must be exceeded if movement of the liquid periphery is accomplished; all apparent angles between these values can exist. These predictions are based upon $(a)$ the assumption that a true and single-valued equilibrium of surface forces exists at all times along the liquid-solid-gas line of contact; $(b)$ the fact that the observed angle is measured from the macroscopic plane of the solid; and $(c)$ the absence of other factors which might influence the hysteresis effect (adsorption, polar heterogeneity, liquid friction).

It is obvious that this simplified picture of physical roughness necessitates that the "average" angles, which are the arithmetic means of the pairs of advancing and receding angles for a given solid, be constant and be equal to the "true" angle. In the present work it was found that the contact angles of water against purified paraffin did give an average angle which was constant. In contrast, contact-angle data on many other systems have indicated that other factors, or additional factors, must be involved. The surfaces of solid, saturated hydrocarbons such as paraffin may, because of their complete and uniform nonpolar character, represent the limiting relationship between hysteresis of the contact angle and physical roughness.

\section{SUMMARY}

The experimental results show that when very thin films of purified paraffin were formed in vacuum by volatilization on smooth glass surfaces and water drops were placed upon them, the advancing and the receding contact angles were sensibly the same, $112^{\circ}$; that is, hysteresis effects did not exist on these very thin and very smooth surfaces.

Measurable hysteresis effects from $5^{\circ}$ to $35^{\circ}$ were found for less smooth films, and coatings of appreciable thickness formed in vacuum, in nitrogen, or in air, whether from a melt or by volatilization.

The magnitude of the hysteresis effects appeared to be closely associated with the microscopic roughness of the surfaces, the roughness adding to the magnitude of the advancing angle but subtracting from the receding angle to the same degree, so that the average angle remained the same for paraffin films of different roughnesses but of the same degree of purification. The average contact angle for purified paraffin was slightly larger than the average angle for unpurified paraffin. 


\section{REFERENCES}

1. Fowkes, F. M., and Harkins, W. D., J. Am. Chem. Soc. 62, 3377 (1940).

2. Thiessen, P. A., AND Schoon, E., Z. Elektrochem. 46, 170 (1940).

3. Barteld, F. E., Culbertson, J. L., And Mrller, M. A., J. Phys. Chem. 40, 881 (1936).

4. Adam, N. K., and Jessop, G., J. Chem. Soc. 127, 1863 (1925).

5. Bartell, F. E., ANd Zuidema, H. H., J. Am. Chem. Soc. 58, 1449 (1936).

6. Bartell, F. E., And Smith, J. T., J. Phys. Chem. 57; 165 (1953).

7. Adam, N. K., The Physies and Chemistry of Surfaces, 3rd Ed., p. 186. Oxford University Press, New York, 1941.

8. Wenzes, R. N., Ind. Eng. Chem. 28, 988 (1936); J. Phys. Chem. 53, 1466 (1949).

9. Coghill, C. O., And Anderson, C. O., U. S. Bur. Mines Tech. Paper No. 262, 47 (1923).

10. Cassie, A. B. D., And Baxter, S., Trans. Faraday Soc. 40, 546 (1944). 